\title{
Recent advances of animal model of focal segmental glomerulosclerosis
}

\author{
Jae Won Yang ${ }^{1} \cdot$ Anne Katrin Dettmar ${ }^{2} \cdot$ Andreas Kronbichler $^{3} \cdot$ Heon Yung Gee ${ }^{4} \cdot$ Moin Saleem ${ }^{5,9}$. \\ Seong Heon $\mathrm{Kim}^{6,7}$. Jae II Shin ${ }^{8}$
}

Received: 23 October 2016 / Accepted: 26 February 2018 / Published online: 20 March 2018

(c) The Author(s) 2018

\begin{abstract}
In the last decade, great advances have been made in understanding the genetic basis for focal segmental glomerulosclerosis (FSGS). Animal models using specific gene disruption of the slit diaphragm and cytoskeleton of the foot process mirror the etiology of the human disease. Many animal models have been developed to understand the complex pathophysiology of FSGS. Therefore, we need to know the usefulness and exact methodology of creating animal models. Here, we review classic animal models and newly developed genetic animal models. Classic animal models of FSGS involve direct podocyte injury and indirect podocyte injury due to adaptive responses. However, the phenotype depends on the animal background. Renal ablation and direct podocyte toxin (PAN, adriamycin) models are leading animal models for FSGS, which have some limitations depending on mice background. A second group of animal models were developed using combinations of genetic mutation and toxin, such as NEP25, diphtheria toxin, and Thy1.1 models, which specifically injure podocytes. A third group of animal models involves genetic engineering techniques targeting podocyte expression molecules, such as podocin, CD2-associated protein, and TRPC6 channels. More detailed information about podocytopathy and FSGS can be expected in the coming decade. Different animal models should be used to study FSGS depending on the specific aim and sometimes should be used in combination.
\end{abstract}

Keywords Animal model $\cdot$ Focal segmental glomerulosclerosis $\cdot$ Podocyte

Seong Heon Kim and Jae Il Shin equally contributed on this manuscript.

Seong Heon Kim pedksh@gmail.com

$\bowtie$ Jae Il Shin

shinji@yuhs.ac

Anne Katrin Dettmar

a.dettmar@uke.de

Andreas Kronbichler

Andreas.Kronbichler@i-med.ac.at

Heon Yung Gee

HYGEE@YUHS.AC

Moin Saleem

moinsaleem@hotmail.com

1 Department of Nephrology, Yonsei University Wonju College of Medicine, Wonju, Gangwon, Republic of Korea

2 Pediatric Nephrology, Department of Pediatrics, Medical University Center Hamburg-Eppendorf, Hamburg, Germany
3 Department of Internal Medicine IV (Nephrology and Hypertension), Universitätskliniken Innsbruck, Anichstraße 35, 6020 Innsbruck, Austria

4 Department of Pharmacology, Yonsei University College of Medicine, Seoul, Republic of Korea

5 Paediatric Renal Medicine, University of Bristol, Bristol, UK

6 Department of Pediatrics, Pusan National University Children's Hospital, Yangsan, Republic of Korea

7 Research Institute for Convergence of Biomedical Science and Technology, Pusan National University Yangsan Hospital, Yangsan, Republic of Korea

8 Department of Pediatrics, Yonsei University College of Medicine, 50 Yonsei-Ro, Seodaemun-gu, Seoul 120-752, Republic of Korea

9 Children's Renal Unit, Bristol Royal Hospital for Children, Bristol, UK 


\section{Introduction: overview of animal models for focal segmental glomerulosclerosis}

Focal segmental glomerulosclerosis (FSGS), first described by Rich in 1957 [1], is currently recognized as one of the most common causes of primary glomerular diseases in adults and its incidence has recently been increasing [2]. FSGS causes asymptomatic proteinuria or nephrotic syndrome (NS) with or without any renal insufficiency. In adults undergoing renal biopsy for the evaluation of proteinuria, FSGS accounts for approx. $35 \%$ of all cases and up to $80 \%$ of cases in African-American patients. In general, FSGS is a progressive form of kidney disease, accounting for $2.3 \%$ of patients with end-stage renal disease (ESRD) [3], and severe proteinuria at the time of diagnosis has been associated with poor renal prognosis [4]. The term FSGS summarizes a unique histological pattern of the glomerular disease, consisting of sclerotic/fibrotic lesion in light microscopy, which can be found in only some (focal) glomeruli and special parts of the single glomerulus (segmental). There are different causes underlying the development of a FSGS pattern, and primary (idiopathic) FSGS has to be distinguished from secondary FSGS caused by known trigger. Regardless of the disease forms, the podocyte stands in the center of the disease and seems to be an important target in FSGS [5]. The pathomechanisms behind the different forms of FSGS disease appears to be similar, resulting in the same histological picture. Therefore, it is justified and absolutely necessary to study the pathophysiology of FSGS across various animal models. Despite the differences in disease characteristic between humans and animals, animal models have been an essential component of medical research for centuries. One of the most important differences is that many animal models reflect secondary FSGS, whereas primary FSGS is much more common disease form in human [6]. However, the final result of the pathology remains the same between the two disease forms, justifying the use of animal models in understanding the underlying mechanisms behind FSGS.

Genetic engineering in mice has recently been developed to advance our knowledge of kidney disease, including FSGS. Historically, the development of major animal models for FSGS involves direct podocyte injury and indirect podocyte injury due to adaptive responses. In both paradigms, recent evidence indicates that podocyte depletion is a major factor mediating proteinuria and glomerulosclerosis. Podocyte-specific toxin models support that podocyte loss is sufficient to cause FSGS in a dose-dependent manner. Knockout and transgenic models have provided proof of concept that mutations in specific podocyte proteins mediate genetic forms of FSGS [7]. In this review, we describe the classic animal models of FSGS and focus on new genetically engineered animal models.

\section{Classic animal models for FSGS}

\section{Renal ablation model}

One of the first animal models created to study glomerular disease was based on renal ablation in rats. The Brenner group demonstrated that alterations in glomerular blood flow caused by renal ablation result in structural lesions. They suggested that sustained single nephron hyperfiltration might result in maladaptive consequences by damaging remnant glomeruli $[8,9]$. The $5 / 6$ nephrectomy model is produced by removing one kidney and ablating $2 / 3$ of the remaining kidney. Alterations in glomerular structure due to severe renal mass reduction had been detected at as early as 2 weeks in this model. At the 7th week, more than $50 \%$ of glomeruli revealed FSGS lesions, and all animals died by 90 days [10]. Most rats are susceptible to glomerulosclerosis, while C57BL/6 mice are highly resistant to the development of glomerulosclerosis. 129/Sv and Swiss-Webster mice are among the few mouse strains susceptible to developing sclerosis [11]. A 4/6 renal mass reduction results in a milder variant of FSGS, without the induction of hypertension [12].

This model mimics secondary FSGS in human due to loss of functional kidney tissue (due to trauma, tumor surgery, severe obesity, and very low birth weight infant), even though the loss of nephron mass is more acute and drastic in the animal model compared to the human disease (Table 1).

\section{Induction of FSGS using podocyte-toxic drugs}

Induction of FSGS-causing agents, specifically toxic to podocytes, can be used to cause FSGS in animals. The severity of FSGS is usually dose dependent, and the development of glomerular disease is reliable and relatively easy to handle in these models. Such models are suitable for studying the effect of protective and curative treatments or for examining the precise pathomechanism of proteinuric nephropathies.

\section{Puromycin aminonucleoside}

Puromycin aminonucleoside (PAN) is an antibiotic that inhibits protein synthesis. PAN nephropathy can be induced in rats through various induction regimen, such multiple intraperitoneal injections or single intravenous administration with or without concomitant unilateral nephrectomy $[13,14]$. Massive proteinuria develops within days of single-dose administration of PAN (50 $\mathrm{mg} / \mathrm{kg}$ body weight), and the kidney shows complete effacement of podocyte foot processes. The early phase of this model resembles minimal change disease in human. A phase of almost complete remission is followed by steady, progressive, lower level proteinuria, developing between weeks 10 and 13, associated 


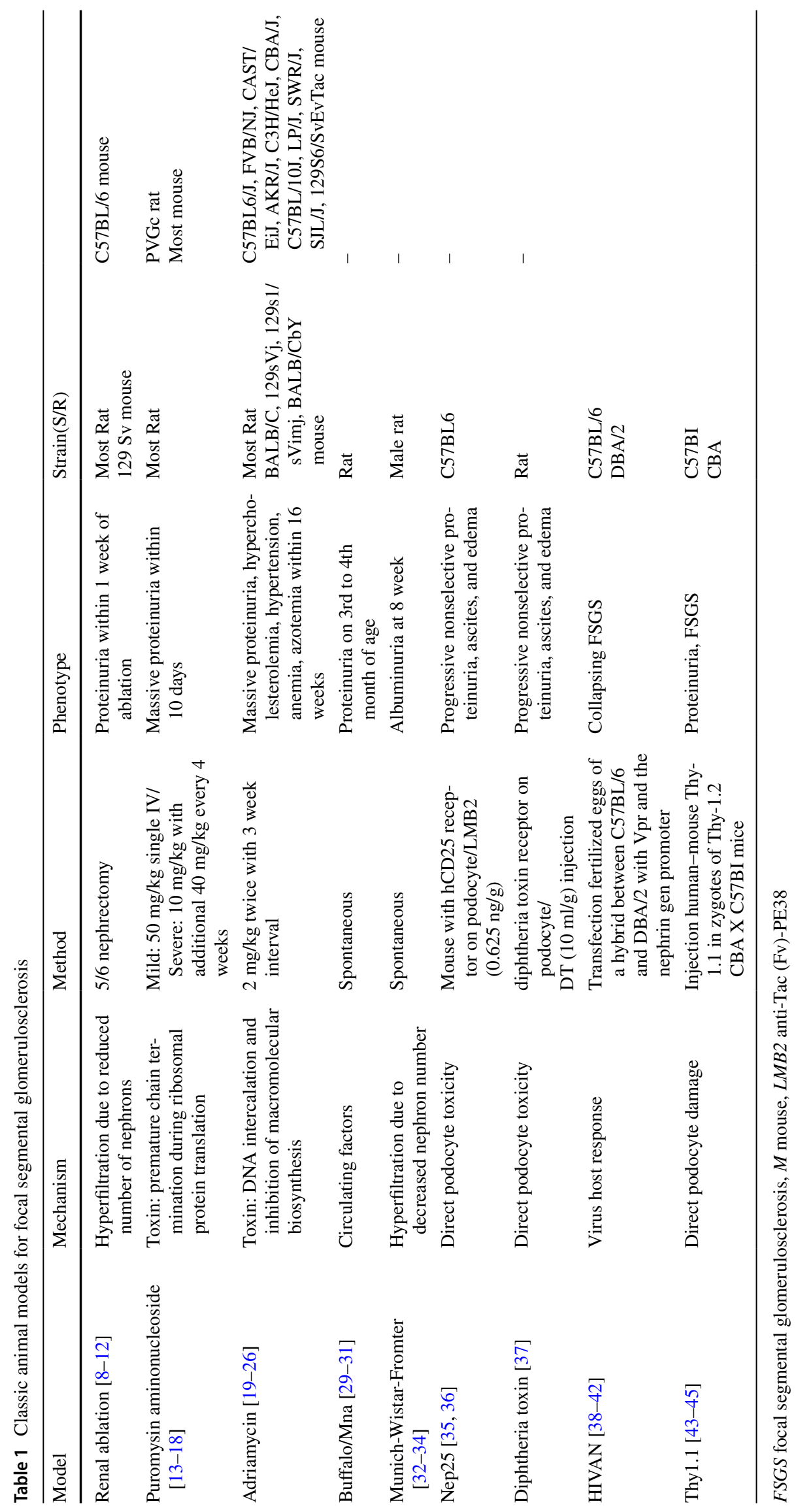


with early FSGS lesions. Follow-up of these animal models months after PAN administration shows glomerular sclerosis and progressive renal failure $[15,16]$. By week 18 , approximately $10-15 \%$ of the glomeruli show well-defined segmental sclerosis. The course is accelerated with uni-nephrectomy and multiple intraperitoneal injections $(10 \mathrm{mg} / \mathrm{kg}$ body weight for the first dose, followed by additional doses of $40 \mathrm{mg} / \mathrm{kg}$ body weight at every 4 week), with well-defined glomerulosclerosis developed by week $8[17,18]$ (Table 1).

\section{Adriamycin model}

Adriamycin is a well-known toxic agent of renal injury in rats, which mirrors histological changes that are observed in human chronic kidney disease (CKD) due to primary FSGS. Sternberg et al. were the first to publicate the use of anthracyclines to cause renal injury [19]. This animal model of kidney disease has several benefits. It is a highly reproducible and a robust tissue injury model associated with little mortality $(<5 \%)$ and morbidity (weight loss) [20]. In male Wistar rats, the dose of adriamycin needed to induce renal injury ranges between 1.5 and $7.5 \mathrm{mg} / \mathrm{kg}$. Male BALB/c mice require $9.8-10.4 \mathrm{mg} / \mathrm{kg}$ of the drug, while only $5.3 \mathrm{mg} /$ $\mathrm{kg}$ is required for male BALB/c SCID mice, an inbred lymphocyte-depleted strain of BALB/c mice. C57BL/c mice are highly resistant to adriamycin-induced renal injury, but renal injury may be inducible at higher doses (13-25 mg/ $\mathrm{kg}$ ) than those required by BALB/c mice [21]. While most studies employ single injection regimen, regimens using multiple injections have also been reported [22-25]. After 16 weeks, the FSGS phenotype is observed with progression to global glomerulosclerosis and tubulointerstitial fibrosis at 24 weeks. Due to increased serum urea levels, some animals do not survive beyond 28 weeks [26].

Similar to Adriamycin, PAN model is directly toxic to podocytes and causes podocyte damage, elevates the endothelial permeability, and so reduces glomerular selectivity, which secondarily leads to tubulointerstitial injury. The biggest disadvantage of these drug-induced models is the uncertainty of their similarity to human pathogenesis of FSGS [20] (Table 1).

\section{Models with spontaneous FSGS}

\section{Buffalo/MWF model}

Buffalo/Mna rats are a strain with a benign thymoma and the spontaneous development of proteinuria and nephrosclerosis [27]. The reason for the development of the FSGS-like lesions is not yet clear, but a circulating nephrotoxic factor in addition to aging and hypertension has been considered, because proteinuria had recurred after kidney transplantation from healthy Lewis rats. This suggested the involvement of a circulating proteinuric factor, which might correspond to relapsing idiopathic nephrotic syndrome in humans. Akiyama et al. found that Arp3 is a candidate for the Pur1 gene, which has been identified in Buffalo/Mna rats through a quantitative trait locus (QTL) for proteinuria. Abnormal signaling-induced assembly of actin in podocytes leads to the development of FSGS [28]. The slower progression of the disease also mimics the slower development in human disease [29, 30]. Nevertheless, the slower pace of deterioration also brings disadvantages for practical research use (Table 1).

\section{Munich-Wistar-Fromter rat}

Munich-Wistar-Fromter (MWF) rats are a strain characterized by a lower nephron count than standard Wistar rats [31]. Quantitative trait mapping and total genome scan reveals a locus on chromosome 6 associated with increased albuminuria [32]. By the early age of 10 weeks, MWF rats develop proteinuria, and their systolic blood pressure (SBP) ranges from 140 to $150 \mathrm{mmHg}$. By 9 months of age, SBP reaches $180 \mathrm{mmHg}$ and the kidney exhibits significant glomerulosclerosis. Notably, these phenomena are more prominent in males than in females despite similar nephron deficit. Higher single nephron glomerular filtration rates and glomerular volume in males than females may contribute to this gender difference [33] (Table 1).

\section{NEP25 mouse model}

The Nep25 mouse model is a model exclusively targeting the podocyte. A transgenic mouse strain (NEP25) that expresses human CD25 selectively in podocytes has been generated [34]. Injection of anti-Tac (Fv)-PE38 (LMB2), an immunotoxin with specific binding to human CD25, induces progressive nonselective proteinuria, ascites, and edema in NEP25 mice. Podocytes in these mice showed foot process effacement, vacuolar degeneration, detachment, and downregulation of synaptopodin, WT-1, nephrin, and podocalyxin. Mesangial cells developed matrix expansion, increased collagen, mesangiolysis, and, later, sclerosis. Parietal epithelial cells showed vacuolar degeneration and proliferation, whereas the endothelial cells were swollen. The severity of glomerular injury was LMB2 dose dependent. Using dosage of at least $1.25 \mathrm{ng} / \mathrm{g}$ body weight, NEP25 mice developed progressive glomerular damage and died within 2 weeks. At dosage of $0.625 \mathrm{ng} / \mathrm{g}$ body weight, NEP25 mice survived for more than 4 weeks and developed focal segmental glomerular sclerosis. Thus, this study established a mouse model of acquired progressive glomerular sclerosis in which onset and severity can be preprogrammed by specific maneuvers [35] (Table 1). 


\section{Diphtheria toxin model}

A transgenic rat strain in which the human diphtheria toxin (DT) receptor is specifically expressed in podocytes was developed. The rodent homologue does not act as a diphtheria toxin receptor, thereby making rodents resistant to DT. Injection of DT $(1 \mathrm{ml} / 10 \mathrm{~g})$ into transgenic rats resulted in dose-dependent podocyte depletion from glomeruli. Three stages of glomerular injury caused by DT-induced podocyte depletion have been identified: Stage 1, 0-20\% depletion with mesangial expansion, transient proteinuria, and normal renal function; stage 2, 21-40\% depletion with mesangial expansion, capsular adhesions (synechiae), focal segmental glomerulosclerosis, mild persistent proteinuria, and normal renal function; and stage 3, $>40 \%$ podocyte depletion with segmental to global glomerulosclerosis with sustained high-grade proteinuria and reduced renal function [36]. This model also is very suitable for research purposes because of its predictability. In addition, it provides important information regarding the development of secondary changes due to podocyte loss, but like many other models, it might not address the primary form of FSGS (Table 1).

\section{HIV-nephropathy model}

HIV-associated nephropathy (HIVAN) is one of the leading causes of ESRD worldwide. Therefore, understanding this particular secondary form of FSGS and mechanisms associated with its aggravation and amelioration is important. To do so, animal models for HIV-induced nephropathy are absolutely essential. There are different virus-induced animal models for FSGS research. Most of them are HIV-1based models. HIVAN transgenic mouse model was created using a replication-deficient version of HIV as the integrated transgene called transgenic 26 (Tg26). Proteinuria was first observed at 24 days of age. Around $20 \%$ of these mice died between 2 and 6 months with increased proteinuria, elevated blood urea nitrogen, edema, ascites, and hypoalbuminemia [37, 38]. Pathologically, the kidneys from uremic animals demonstrate collapsing lesions at a certain time point, diffuse segmental and global glomerulosclerosis, and microcystic tubular dilatation. These changes are remarkably similar to HIVAN [39, 40]. HIVAN probably develops because of the direct infection of podocytes and the local release of inflammatory cytokines. The HIV-1 transgenic mouse model demonstrated an immediate etiologic link between HIV-1 inclusion into glomerular cells and the secondary development of HIVAN with unique viral-host interactions. Both stimulating features of the virus and the individual nature of the host response contribute to this interaction. Infection of renal cells by HIV-1 was detected by RT-PCR of gag RNA at a low level. Some studies using HIV-1 transgenic mouse models have shown that the invasion of HIV-1 in kidneys is required for development of HIVAN. The final common pathway in the development of HIVAN most likely involves altered patterns of gene expression in renal parenchyma cells caused by cytokines and growth factors, leading to interstitial fibrosis and enhanced glomerular matrix synthesis. The nature of the host response to viral infection is critical to the development of nephropathy [41] (Table 1).

\section{Thy-1.1 transgenic mouse model}

The Thy-1.1 transgenic mouse is a podocyte-specific injury model, which should not be confused with the Thy1.1 rat model. Kollias et al. generated transgenic mice for a hybrid gene composed of the $5^{\prime}$ part of mouse Thy-1.1 gene combined with $3^{\prime}$ human untranslated regions. Ectopic expression of the Thy-1.1 transgene induced spontaneous development of albuminuria within 8 weeks after birth and induced FSGS lesions in approximately $20 \%$ of glomeruli at 6 months of age [42]. In 2002, Assman et al. established an inducible model of FSGS in heterozygous animals by the injection of anti-Thy-1.1 monoclonal antibodies. Animals developed acute proteinuria caused by the damage of podocytes and parietal cells in dose-dependent manner. It is an excellent inducible model to study the relationship between podocyte injury, albuminuria, and the development of FSGS $[43,44]$ (Table 1).

\section{New genetically engineered mouse models for FSGS}

Genetic engineering in animal models revealed the possibility of studying functions of many novel genes and proteins. However, so far, mutations can be identified only in a minority of patients with FSGS patients. Nevertheless, these animal models are essential in investigating functions of a single protein or protein-protein interactions as well as their consequences to determine the prognosis of the underlying disease. We focused on phenotypic FSGS models with podocyte abnormalities and finally glomerulosclerosis excluding just only proteinuria.

\section{Actin cytoskeleton}

\section{a-Actinin 4 model}

$\alpha$-Actinin 4 is an actin-associated cross-linking protein. Patients with mutations in $\alpha$-actinin 4 gene develop FSGS with an autosomal dominant inheritance pattern. The mutant protein leads to impaired dynamics of the actin cytoskeleton in podocytes and deterioration of podocyte slit diaphragm, resulting in early development of proteinuria and FSGS. Knock-in-mouse models have been generated to examine 
the role of different human mutations [45, 46]. These studies helped to identify the purpose and physiological role of this cross-linking protein and the consequence and the severity of point mutations [47, 48] (Table 2; Fig. 1).

\section{Myosin 1e model}

Myosin 1e (Myo1e) is one of the two Src homology 3 domain-containing "long-tailed" type I myosins in

Table 2 Comparison of genetics between animal model and human model for FSGS

\begin{tabular}{|c|c|c|}
\hline Animal model & Human model & Affected location \\
\hline$\alpha$-Actinin-4 [46-48] & $\alpha$-Actinin-4 [45] & $\begin{array}{l}\text { Actin filament cross-linking protein/Interacts with integ- } \\
\text { rins and strengthens the podocyte-GBM interaction }\end{array}$ \\
\hline Atypical protein kinase C [68-71] & & $\begin{array}{l}\text { Tight junctions/Formation of Par complex and interacts } \\
\text { with slit diaphragm }\end{array}$ \\
\hline Rhophilin-1 [80] & Rho GTPase activating protein 24 [80] & $\begin{array}{l}\text { Cytoplasm/Rho GTPase-interacting protein, integrity of } \\
\text { glomerular filtration barrier }\end{array}$ \\
\hline Angiotensin II receptor [55-57] & Angiotensin-converting enzyme [55-57] & Membrane/pseudocyst formation at podocyte \\
\hline CD2-associated protein [65-67] & CD2-associated protein $[64]$ & $\begin{array}{l}\text { Insertion site of the slit diaphragm/Formation SD com- } \\
\text { plex with podocin and nephrin }\end{array}$ \\
\hline Laminin subunit beta-2 [81-84] & Laminin subunit beta-2 [81-84] & Podocyte anchoring and differentiation in GBM \\
\hline microRNA $193 \alpha[74,75]$ & & Cytoplasm/Inhibition of expression of WT-1 \\
\hline Myosin 1e $[49,50]$ & Myosin 1e $[49,50]$ & $\begin{array}{l}\text { Actin binding long-tailed motor protein/Regulation of } \\
\text { actin cytoskeleton }\end{array}$ \\
\hline Nuclear factor of activated T cells $[76,77]$ & Transient receptor potential $6[53,54]$ & $\begin{array}{l}\text { Membrane/the activation of calcineurin-NFAT/Wnt sign- } \\
\text { aling via the increased calcium influx }\end{array}$ \\
\hline Podocin [46] & Podocin $[58,59]$ & $\begin{array}{l}\text { Insertion site of the SD/SD assembly and maintaining the } \\
\text { signaling of nephrin }\end{array}$ \\
\hline Shroom family member $3[51,52]$ & Shroom family member $3[51,52]$ & Actin filament development/glomerular sclerosis \\
\hline Transcription factor 21(Pod1) [78] & & $\begin{array}{l}\text { Cytoplasm/Development of endothelial and mesangial } \\
\text { cell }\end{array}$ \\
\hline \multirow[t]{2}{*}{ Van Gogh-like protein $2[72,73]$} & & $\begin{array}{l}\text { SD/Planar cell polarity signaling pathway for morpho- } \\
\text { genesis }\end{array}$ \\
\hline & Wilms tumor suppressor 1 [79] & Downregulation of nephrin and synaptopodin \\
\hline
\end{tabular}

$N S$ nephrotic syndrome, $F S G S$ focal segmental glomerulosclerosis, $M$ mouse, $S D$ slit diaphragm, $G B M$ glomerular basement membrane

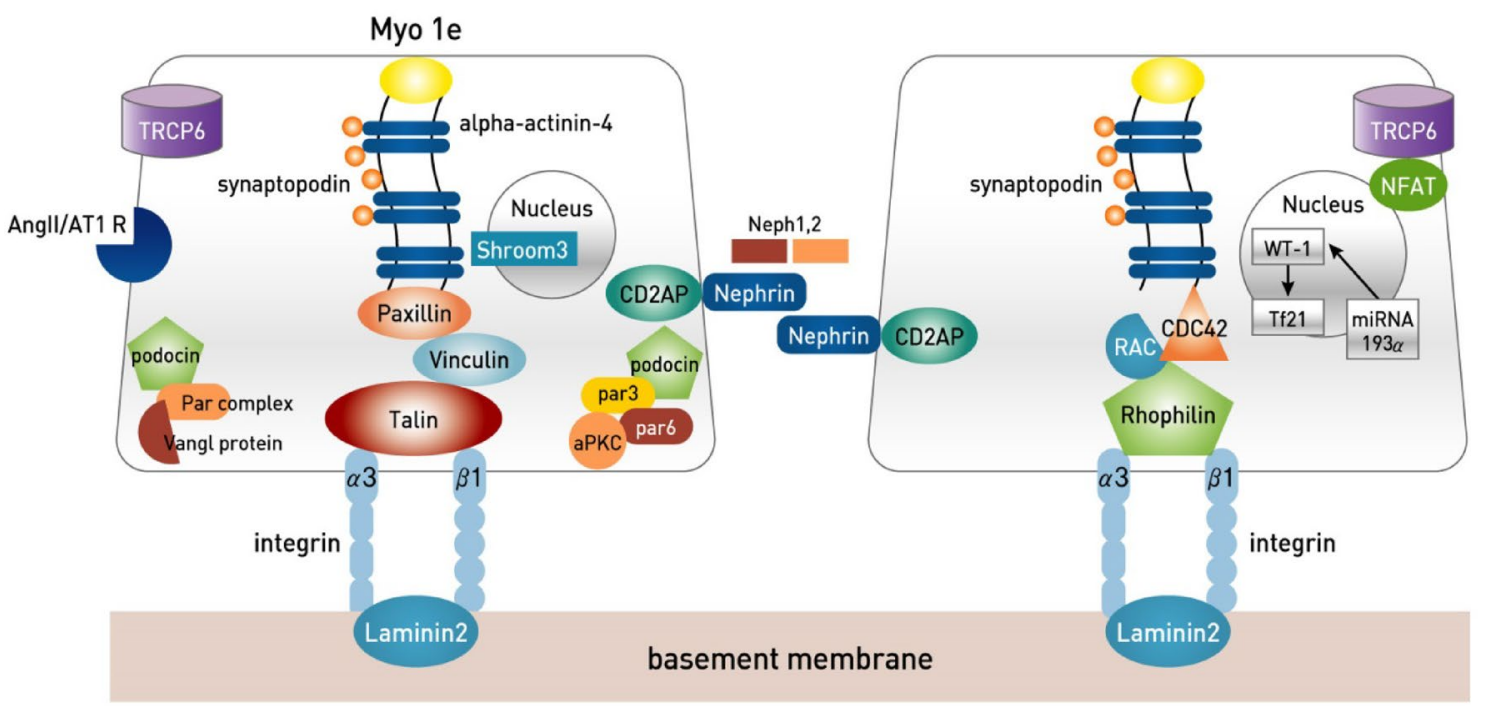

Fig. 1 Schematic diagram of genetically affected location for FSGS model. Myo 1e myosin 1e, TRCP6 transient receptor potential 6, AngII/ATIR angiotensin II/angiotensin receptor 1, Vangl protein Van
Gogh-like protein, $a P K C$ atypical protein kinase C, WT-1 Wilm's tumor suppressor-1, NFAT nuclear factor of activated T cell, Tf21 transcription factor 21, miRNA 193 $\alpha$ microRNA $193 \alpha$ 
vertebrates. Myole-KO mice exhibited proteinuria, signs of chronic renal injury, and kidney inflammation. Renal tissue from Myo1e-null mice demonstrated histological characteristic of glomerular disease at ultrastructural level, including a thickened and disorganized glomerular basement membrane and flattened podocyte foot processes [49]. Myo1e in humans has an important role in podocyte function and the consequent integrity of glomerular permselectivity barrier. The mutation leads to childhood onset steroid-resistant FSGS [50] (Table 2; Fig. 1).

\section{Shroom 3}

Shroom3 is an actin-associated protein that regulates epithelial cell and tissue morphogenesis by binding $\mathrm{F}$ actin and regulating its subcellular organization. Shroom3 interacts and recruits Rho-kinase (Rock), resulting in the phosphorylation and activation of nonmuscle myosin II (MyoII). Activation of this Rock/MyoII signaling pathway causes localized contraction of actin-myosin networks at the apical surface of the podocyte, resulting in changes in cell morphology [51]. In addition, Shroom3 heterozygous (Shroom3Gt/+) mice showed developmental abnormalities that manifested as adult-onset glomerulosclerosis and proteinuria [52] (Table 2; Fig. 1).

\section{Apical cell surface}

\section{Transient receptor potential channel 6 model}

The latest advance in familial FSGS has been the discovery of a mutant form of canonical transient receptor potential cation channel 6 (TRPC6). This mutation leads to a gain of function and a transient increase of intracellular calcium concentration [53]. Krall et al. described the generation and phenotypic characterization of three different transgenic mice lines with podocyte-specific overexpression of the wild type or any of two mutant forms of Trpc6 (P111Q and E896K) previously related to FSGS. Subnephrotic-range albuminuria was detected in almost all transgenic lines, similar to human phenotype. Histologically, these transgenic mice developed patterns of kidney disease similar to human FSGS. Transgenic mice showed 2-3-folds greater glomerular lesions than non-transgenic mice [54] (Table 2; Fig. 1).

\section{Angiotensin II type 1 receptor}

A novel transgenic rat model with an overexpression of the human AngII type 1 receptor (hAT1) in podocytes was developed to study the consequences of increased AT1 signaling on the structure and function of the glomerular filter. Structural changes at the glomerulus were encountered, starting with ubiquitous formation of pseudocysts at podocytes followed by foot process effacement and local detachments. This damage progressed to nephron loss via the well-known pathway typical for classic FSGS [55]. To evaluate angiotensin-converting enzyme (ACE) gene insertion/deletion polymorphism in nephrotic syndrome, Lee et al. examined 85 patients (minimal change nephrotic syndrome [MCNS]: 55 cases, FSGS: 30 cases) and 61 controls. The distribution of ACE genotype in the control group was II $44 \%$, ID $41 \%$, and DD $15 \%$. While the distribution of ACE genotypes in MCNS was similar to that in controls, the polymorphism pattern in FSGS was markedly different. The DD genotype was more frequent $(p<0.05)$ in FSGS than in MCNS. Patients with the DD genotype tended to present with earlier clinical symptoms. DD genotypes also showed lower responsiveness to corticosteroid therapy and a higher incidence of chronic renal failure. These results indicate that the ACE DD genotype in FSGS may be a risk factor for poor response to steroid therapy and the development of chronic renal failure [56]. However, the D allele or DD homozygosity may become a significant genetic molecular marker for the onset of FSGS in Asians but not for Caucasians, Africans, Arabs, or Jews [57] (Table 2; Fig. 1).

\section{Slit diaphragm}

\section{Nphs2 (podocin) model}

Podocin is encoded by NPHS2 gene. It is a protein expressed at the site of slit diaphragm (SD) insertion in podocyte and is considered critical for SD assembly and nephrin signaling (46). Patients with mutations in the podocin gene develop familial and sporadic forms of FSGS. Since podocin-KO mice die within a few days of birth, the effect of its deficiency on kidney function could not be investigated until recently [58]. Utilization of inducible Cre recombinase technology enabled the creation of a mouse model of podocinrelated NS through elective inactivation of podocin in mature mouse kidneys. Postnatal inactivation of podocin in mature kidneys by elective Cre induction led to massive proteinuria, glomerulosclerosis, and death in renal failure within a median of 11 weeks [59]. Nephrin (encoded by the NPHS1 gene) was identified as the cause of disease in congenital NS of the Finnish type [60]. Nephrin-KO mouse model confirmed the essential role of nephrin in SD structure and function $[61,62]$. NPHS1-KO or inducible mice showed podocyte effacement with proteinuria and early postnatal death, making it unsuitable for animal model of FSGS [63] (Table 2; Fig. 1).

\section{CD2-associated protein model}

$\mathrm{CD} 2$-associated protein (CD2AP) is highly expressed in the glomerulus, binds to nephrin via its c-terminal domain, and 
is localized to the SD [64]. Mice-lacking CD2AP had intact kidneys at birth, but foot process effacement developed after 1 week. Proteinuria appeared at 2 weeks of age, and marked mesangial expansion occurred after 4 weeks. Few patients were identified with mutations for CD2AP [65]. Nonetheless, it still remains unclear how this mutation actually causes FSGS in humans [66]. Heterozygous CD2AP KO mice have been crossed with mice, heterozygous for mutations in other podocyte genes such as Fyn or synaptopodin, also causing proteinuria and FSGS. Partial dysfunction of various podocyte proteins might synergistically predispose to NS [67] (Table 2; Fig. 1).

\section{Atypical protein kinase $\mathrm{C}$ model}

Atypical protein kinase C (aPKC), a component of the Par complex, localizes to tight junctions and interacts SD proteins [68]. aPKC isoforms orchestrate formation of the podocyte processes essential for normal glomerular development and kidney function. Defective aPKC signaling resulted in dramatically simplified glomerular architecture, leading to severe proteinuria and perinatal death $[69,70]$. The regulation of SD turnover by aPKC is crucial for maintenance of SD integrity, and defects in aPKC signaling can cause proteinuria [71] (Table 2; Fig. 1).

\section{Van Gogh-like protein 2}

The planar cell polarity (PCP) signaling pathway is crucial for tissue morphogenesis. Van Gogh-like protein 2 (Vangl2) is central in the PCP pathway. PCP signaling may be important in kidneys for proper tubular morphogenesis and organization of glomerular epithelial cells along the glomerular basement membrane. Podocyte-specific deletion of Vang12 led to glomerular maturation defects in fetal kidneys. In adult mice, significantly smaller glomeruli were detected, but it did not affect glomerular permselectivity in aging animals. In the context of glomerular injury induced by injection of anti-glomerular basement membrane antibody, deletion of Vang12 resulted in injury exacerbation and accelerated progression to chronic segmental and global glomerular sclerosis [72, 73] (Table 2; Fig. 1).

\section{Nucleus}

\section{miRNA 193a (tg) model}

miR-193a inhibits the expression of Wilms' tumor protein (WT1), a transcription factor and master regulator of podocyte differentiation and homeostasis. Decreased expression levels of WT1 lead downregulation of its target genes, specifically PODXL (podocalyxin) and NPHS1 (nephrin), as well as several other genes crucial for podocyte architecture, initiating a catastrophic collapse of the entire podocytestabilizing system [74]. In mice, inhibition of miR-193a by complementary-locked nucleic acids resulted in the upregulation of the podocyte proteins synaptopodin and WT1. Conversely, the overexpression of miR-193a in isolated glomeruli resulted in vivo in up-regulation of parietal epithelial cell (PEC) markers and loss of podocyte markers. Inhibition of miR-193a in mouse model of nephrotoxic nephritis resulted in reduced crescent formation and decreased proteinuria [75] (Table 2; Fig. 1).

\section{Nuclear factor of activated T cells (NFAT), cytoplasmic 1 model}

Mutant forms of TRPC6 can activate nuclear factor of activated T-cell (NFAT)-dependent transcription in vitro via calcium influx and calcineurin activation. These TRPC6 mutants can also cause FSGS, implying that NFAT activation may be a key intermediate step in the pathogenesis of mutant TRPC6-mediated FSGS. Wang et al. established a model of inducible NFAT activation, which revealed the influence of NFAT activation in TRPC6 mutations. Suppression of NFAT activity may contribute to the anti-proteinuric effects of calcineurin inhibitors [76, 77] (Table 2; Fig. 1).

\section{Transcription factor 21 (Pod1) model}

Tcf21 is a basic helix-loop-helix (bHLH) transcription factor which is highly expressed in developing and mature podocytes. Deletion of Tcf 21 from podocytes and podocyte progenitors using podocin-cre (podTcf21) and wnt4cre (wnt4creTcf21) driver strains, respectively, caused loss of Tcf21 from capillary-loop stage podocytes (podTcf21), resulting in simplified glomeruli with a decreased number of endothelial and mesangial cells. By 5 weeks of age, $40 \%$ of podTcf 21 mice develop massive proteinuria and lesions similar to those of FSGS [78] (Table 2; Fig. 1).

\section{Wilms tumor 1}

Hall et al. reported a missense mutation of the transcriptional regulator Wilms' Tumor 1 (WT1) as the cause of non-syndromic, autosomal dominant FSGS in two Northern European kindreds from the United States. They performed sequential genome-wide linkage analysis and whole-exome sequencing to evaluate participants from family DUK6524. They identified a segregating missense mutation (R458Q) in WT1 isoform D as the cause of FSGS in this family. WT1 (R458Q) overexpression significantly downregulated nephrin and synaptopodin expression, promoted apoptosis in HEK293 cells, and impaired focal contact formation in podocytes. This mutation can alter the regulation of 
podocyte homeostasis and causes non-syndromic FSGS [79] (Table 2; Fig. 1).

\section{Basement membrane}

\section{Rhophilin-1 model}

Rhophilin-1 is a Rho GTPase-interacting protein, and its action on cytoskeleton organization is associated with inhibitory effects on Rho-dependent phosphorylation of the myosin regulatory light chain and stress fiber formation. Conversely, phosphorylation of myosin regulatory light chain was increased in podocyte foot processes of Rhpn1(-/-) mice, implicating altered actinomyosin contractility in foot process effacement and compromised filtration capacity. Rhophilin-1 KO mice were phenotypically normal at birth, but developed albuminuria at about 2 weeks of age. Kidneys from severely albuminuric mice revealed widespread podocyte foot process effacement, thickening of the glomerular basement membrane, and FSGS-like lesions. Rhophilin-1 is essential for the integrity of the glomerular filtration barrier and is a key determinant of podocyte cytoskeleton architecture [80] (Table 2; Fig. 1).

\section{Laminin beta2}

Laminin beta2 is known to be abundantly expressed in the glomerular basement membrane and has a key role in anchoring as well as differentiation of podocyte foot processes. Lamb2 knockout mice were reported to exhibit congenital nephrosis in association with anomalies of retina and neuromuscular junctions [81]. Pierson syndrome is a rare autosomal recessive disorder which is mainly characterized by congenital nephrotic syndrome (CNS), diffuse mesangial sclerosis (DMS), and distinct ocular abnormalities, including microcoria. Most affected children exhibit early onset of chronic renal failure, neurodevelopmental deficits, and blindness. It is caused by a homozygous or compound heterozygous mutation in the gene encoding laminin beta2 (LAMB2) on chromosome 3p21 [82, 83]. This mutation was proved in animal model which showed mesangial sclerosis and highly expressed LMB2 in basement membrane [84] (Table 2; Fig. 1).

\section{Correlation with human FSGS subtype}

The Columbia classification proposed in 2004 classified FSGS according to the morphology and intraglomerular location of sclerotic lesions. Five variants, namely, collapsing, tip, cellular, perihilar, and not otherwise specified variants, were proposed [85]. Certain clinical situation is associated with specific variants. For example, collapsing variant, which is reported to result in the worst clinical outcome, is frequently associated with human immunodeficiency virus infection, while tip variant shows good response to treatment [86]. Although relatively little attention has been paid to morphologic subtypes of FSGS in animal models, some models were found to mimic certain variants of human FSGS. Collapsing variant has been most actively studied in terms of the pathogenesis of FSGS, focusing on the role of parietal epithelial cells [87]. In addition, perihilar variant was observed in renal ablation models, and tip variant was associated with intraglomerular shear reflecting the underlying pathogenetic mechanisms of these variants [88].

\section{The relationship between steroid-resistant minimal change disease (MCD) and FSGS}

We excluded animal models which showed only proteinuria or MCD features without glomerulosclerosis. In steroidresistant-type MCD, some genetic factors were proved by humanized mouse, which may be a good model that well reflects MCD pathophysiology to investigate suggested " $\mathrm{T}$ cell dysfunction" directly related to podocytes in vivo [89]. Several candidate circulating factors and their effects on podocytes have been proposed, but are still not sufficient to explain whole mechanisms and clinical features in $\mathrm{MCD}$ [90]. In FSGS, it is not clear if this is a distinct entity, or on the same spectrum, implicating the same circulating factors. These patients are mostly steroid resistant and often have a rapid relapse after transplantation [90]. The 45 genes currently associated with human NS explain not more than $20-30 \%$ of hereditary and only $10-20 \%$ of sporadic cases [91]. Therefore, we need more detail explanation of pathomechanisms including genetic and immunologic combination studies for FSGS and steroid-resistant MCD.

\section{Conclusion and future aspect}

Although the pathomechanism of FSGS development is very complex, classic and new genetic models have allowed significant progress within the past several decades. Animal models of FSGS can now explain mechanisms involved in many secondary forms of chronic kidney disease with proteinuria. These models should provide a basis on which further progress of methodology in elucidating the pathophysiology of podocytopathy can be made. Based on evidences obtained from these animal models and observations in humans, the specific podocytopathy of kidney disease will be determined, allowing study of therapeutic options. 


\section{Compliance with ethical standards}

Conflict of interest The authors have declared that no conflict of interest exists.

Ethical approval This article does not contain any studies with human participants performed by any of the authors

Informed consent Informed consent was obtained from all individual participants included in the study.

Open Access This article is distributed under the terms of the Creative Commons Attribution 4.0 International License (http://creativeco mmons.org/licenses/by/4.0/), which permits unrestricted use, distribution, and reproduction in any medium, provided you give appropriate credit to the original author(s) and the source, provide a link to the Creative Commons license, and indicate if changes were made.

\section{References}

1. Rich AR. A hitherto undescribed vulnerability of the juxtamedullary glomeruli in lipoid nephrosis. Bull Johns Hopkins Hosp. 1957;100(4):173-86.

2. Haas M, Spargo BH, Coventry S. Increasing incidence of focalsegmental glomerulosclerosis among adult nephropathies: a 20-year renal biopsy study. Am J Kidney Dis. 1995;26(5):740-50.

3. Kitiyakara C, Eggers P, Kopp JB. Twenty-one-year trend in ESRD due to focal segmental glomerulosclerosis in the United States. Am J Kidney Dis. 2004;44(5):815-25.

4. D'Agati VD, Kaskel FJ, Falk RJ. Focal segmental glomerulosclerosis. N Engl J Med. 2011;365(25):2398-411. https://doi. org/10.1056/NEJMra1106556.

5. Jefferson JA, Shankland SJ. The pathogenesis of focal segmental glomerulosclerosis. Adv Chronic Kidney Dis. 2014;21(5):408-16. https://doi.org/10.1053/j.ackd.2014.05.009.

6. de Mik SM, Hoogduijn MJ, de Bruin RW, Dor FJ. Pathophysiology and treatment of focal segmental glomerulosclerosis: the role of animal models. BMC Nephrol. 2013;14:74. https://doi. org/10.1186/1471-2369-14-74.

7. D'Agati VD. Podocyte injury in focal segmental glomerulosclerosis: Lessons from animal models (a play in five acts). Kidney Int. 2008;73(4):399-406. https://doi.org/10.1038/sj.ki.5002655.

8. Deen WM, Maddox DA, Robertson CR, Brenner BM. Dynamics of glomerular ultrafiltration in the rat. VII. Response to reduced renal mass. Am J Physiol. 1974;227(3):556-62.

9. Hostetter TH, Olson JL, Rennke HG, Venkatachalam MA, Brenner BM. Hyperfiltration in remnant nephrons: a potentially adverse response to renal ablation. Am J Physiol. 1981;241(1):F85-93.

10. Purkerson ML, Hoffsten PE, Klahr S. Pathogenesis of the glomerulopathy associated with renal infarction in rats. Kidney Int. 1976;9(5):407-17.

11. Ma LJ, Fogo AB. Model of robust induction of glomerulosclerosis in mice: importance of genetic background. Kidney Int. 2003;64(1):350-5. https://doi.org/10.104 6/j.1523-1755.2003.00058.x.

12. Matsuguma K, Ueda S, Yamagishi S, Matsumoto Y, Kaneyuki $\mathrm{U}$, Shibata R, et al. Molecular mechanism for elevation of asymmetric dimethylarginine and its role for hypertension in chronic kidney disease. J Am Soc Nephrol. 2006;17(8):2176-83. https:// doi.org/10.1681/ASN.2005121379.
13. Grond J, Weening JJ, van Goor H, Elema JD. Application of puromycin aminonucleoside and adriamycin to induce chronic renal failure in the rat. Contrib Nephrol. 1988;60:83-93.

14. Rossmann P, Bukovsky A, Matousovic K, Holub M, Kral J. Puromycin aminonucleoside nephropathy: ultrastructure, glomerular polyanion, and cell surface markers. J Pathol. 1986;148(4):33748. https://doi.org/10.1002/path.1711480410.

15. Diamond JR, Karnovsky MJ. Focal and segmental glomerulosclerosis following a single intravenous dose of puromycin aminonucleoside. Am J Pathol. 1986;122(3):481-7.

16. Furness PN, Harris K. An evaluation of experimental models of glomerulonephritis. Int J Exp Pathol. 1994;75(1):9-22.

17. Anderson S, Diamond JR, Karnovsky MJ, Brenner BM. Mechanisms underlying transition from acute glomerular injury to late glomerular sclerosis in a rat model of nephrotic syndrome. J Clin Invest. 1988;82(5):1757-68. https://doi.org/10.1172/JCI11 3789.

18. Glasser RJ, Velosa JA, Michael AF. Experimental model of focal sclerosis. I. Relationship to protein excretion in aminonucleoside nephrosis. Lab Invest. 1977;36(5):519-26.

19. Sternberg SS. Cross-striated fibrils and other ultrastructural alterations in glomeruli of rats with daunomycin nephrosis. Lab Invest. 1970;23(1):39-51.

20. Lee VW, Harris DC. Adriamycin nephropathy: a model of focal segmental glomerulosclerosis. Nephrology (Carlton). 2011;16(1):30-8. https://doi.org/10.1111/j.1440-1797.2010.01383 .x.

21. Lombardi D, Lasagni L. Transgenic strategies to study podocyte loss and regeneration. Stem Cells Int. 2015;2015:678347. https:// doi.org/10.1155/2015/678347.

22. Hayashi K, Sasamura H, Ishiguro K, Sakamaki Y, Azegami T, Itoh $\mathrm{H}$. Regression of glomerulosclerosis in response to transient treatment with angiotensin II blockers is attenuated by blockade of matrix metalloproteinase-2. Kidney Int. 2010;78(1):69-78. https ://doi.org/10.1038/ki.2010.81.

23. Heikkila E, Juhila J, Lassila M, Messing M, Perala N, Lehtonen E, et al. beta-Catenin mediates adriamycin-induced albuminuria and podocyte injury in adult mouse kidneys. Nephrol Dial Transplant. 2010;25(8):2437-46. https://doi.org/10.1093/ndt/gfq076.

24. Jeansson M, Bjorck K, Tenstad O, Haraldsson B. Adriamycin alters glomerular endothelium to induce proteinuria. J Am Soc Nephrol. 2009;20(1):114-22. https://doi.org/10.1681/ASN.20071 11205.

25. Lee VW, Wang Y, Qin X, Wang Y, Zheng G, Mahajan D, et al. Adriamycin nephropathy in severe combined immunodeficient (SCID) mice. Nephrol Dial Transplant. 2006;21(11):3293-8. https ://doi.org/10.1093/ndt/gfl413.

26. Bertani T, Rocchi G, Sacchi G, Mecca G, Remuzzi G. Adriamycin-induced glomerulosclerosis in the rat. Am J Kidney Dis. 1986;7(1):12-9.

27. Nakamura T, Oite T, Shimizu F, Matsuyama M, Kazama T, Koda $\mathrm{Y}$, et al. Sclerotic lesions in the glomeruli of Buffalo/Mna rats. Nephron. 1986;43(1):50-5.

28. Akiyama K, Morita H, Suetsugu S, Kuraba S, Numata Y, Yamamoto $\mathrm{Y}$, et al. Actin-related protein 3 (Arp3) is mutated in proteinuric BUF/Mna rats. Mamm Genome. 2008;19(1):41-50. https ://doi.org/10.1007/s00335-007-9078-5.

29. Le Berre L, Godfrin Y, Gunther E, Buzelin F, Perretto S, Smit $\mathrm{H}$, et al. Extrarenal effects on the pathogenesis and relapse of idiopathic nephrotic syndrome in Buffalo/Mna rats. J Clin Invest. 2002;109(4):491-8. https://doi.org/10.1172/JCI12858.

30. Le Berre L, Godfrin Y, Perretto S, Smit H, Buzelin F, Kerjaschki D, et al. The Buffalo/Mna rat, an animal model of FSGS recurrence after renal transplantation. Transplant Proc. 2001;33(7-8):3338-40. 
31. Fassi A, Sangalli F, Maffi R, Colombi F, Mohamed EI, Brenner BM, et al. Progressive glomerular injury in the MWF rat is predicted by inborn nephron deficit. J Am Soc Nephrol. 1998;9(8):1399-406.

32. Schulz A, Standke D, Kovacevic L, Mostler M, Kossmehl P, Stoll $\mathrm{M}$, et al. A major gene locus links early onset albuminuria with renal interstitial fibrosis in the MWF rat with polygenetic albuminuria. J Am Soc Nephrol. 2003;14(12):3081-9.

33. Schulz A, Litfin A, Kossmehl P, Kreutz R. Genetic dissection of increased urinary albumin excretion in the munich wistar fromter rat. J Am Soc Nephrol. 2002;13(11):2706-14.

34. Matsusaka T, Xin J, Niwa S, Kobayashi K, Akatsuka A, Hashizume $\mathrm{H}$, et al. Genetic engineering of glomerular sclerosis in the mouse via control of onset and severity of podocyte-specific injury. J Am Soc Nephrol. 2005;16(4):1013-23. https://doi. org/10.1681/ASN.2004080720.

35. Miyazaki Y, Shimizu A, Ichikawa I, Hosoya T, Pastan I, Matsusaka T. Mice are unable to endogenously regenerate podocytes during the repair of immunotoxin-induced glomerular injury. Nephrol Dial Transplant. 2014;29(5):1005-12. https://doi. org/10.1093/ndt/gft413.

36. Wharram BL, Goyal M, Wiggins JE, Sanden SK, Hussain S, Filipiak WE, et al. Podocyte depletion causes glomerulosclerosis: diphtheria toxin-induced podocyte depletion in rats expressing human diphtheria toxin receptor transgene. J Am Soc Nephrol. 2005;16(10):2941-52. https://doi.org/10.1681/ASN.2005010055.

37. Kajiyama W, Kopp JB, Marinos NJ, Klotman PE, Dickie P. Glomerulosclerosis and viral gene expression in HIV-transgenic mice: role of nef. Kidney Int. 2000;58(3):1148-59. https://doi.org/10.1 046/j.1523-1755.2000.00271.x.

38. Rosenstiel P, Gharavi A, D'Agati V, Klotman P. Transgenic and infectious animal models of HIV-associated nephropathy. J Am Soc Nephrol. 2009;20(11):2296-304. https://doi.org/10.1681/ ASN.2008121230.

39. Kopp JB, Klotman ME, Adler SH, Bruggeman LA, Dickie P, Marinos NJ, et al. Progressive glomerulosclerosis and enhanced renal accumulation of basement membrane components in mice transgenic for human immunodeficiency virus type 1 genes. Proc Natl Acad Sci USA. 1992;89(5):1577-81.

40. Lu TC, He JC, Klotman P. Animal models of HIV-associated nephropathy. Curr Opin Nephrol Hypertens. 2006;15(3):233-7. https://doi.org/10.1097/01.mnh.0000222688.69217.8e.

41. Avila-Casado C, Fortoul TI, Chugh SS. HIV-associated nephropathy: experimental models. Contrib Nephrol. 2011;169:270-85. https://doi.org/10.1159/000320212.

42. Kollias G, Evans DJ, Ritter M, Beech J, Morris R, Grosveld F. Ectopic expression of Thy-1 in the kidneys of transgenic mice induces functional and proliferative abnormalities. Cell. 1987;51(1):21-31.

43. Assmann KJ, van Son JP, Dijkman HB, Mentzel S, Wetzels JF. Antibody-induced albuminuria and accelerated focal glomerulosclerosis in the Thy-1.1 transgenic mouse. Kidney Int. 2002;62(1):116-26. https://doi.org/10.104 6/j.1523-1755.2002.00428.x.

44. Smeets B, Dijkman HB, te Loeke NA, van Son JP, Steenbergen EJ, Assmann KJ, et al. Podocyte changes upon induction of albuminuria in Thy-1.1 transgenic mice. Nephrol Dial Transplant. 2003;18(12):2524-33.

45. Kaplan JM, Kim SH, North KN, Rennke H, Correia LA, Tong $\mathrm{HQ}$, et al. Mutations in ACTN4, encoding alpha-actinin-4, cause familial focal segmental glomerulosclerosis. Nat Genet. 2000;24(3):251-6. https://doi.org/10.1038/73456.

46. Kos CH, Le TC, Sinha S, Henderson JM, Kim SH, Sugimoto $\mathrm{H}$, et al. Mice deficient in alpha-actinin-4 have severe glomerular disease. J Clin Invest. 2003;111(11):1683-90. https://doi. org/10.1172/JCI17988.
47. Yao J, Le TC, Kos CH, Henderson JM, Allen PG, Denker BM, et al. Alpha-actinin-4-mediated FSGS: an inherited kidney disease caused by an aggregated and rapidly degraded cytoskeletal protein. PLoS Biol. 2004;2(6):e167. https://doi.org/10.1371/journ al.pbio.0020167.

48. Michaud JL, Lemieux LI, Dube M, Vanderhyden BC, Robertson SJ, Kennedy CR. Focal and segmental glomerulosclerosis in mice with podocyte-specific expression of mutant alpha-actinin-4. J Am Soc Nephrol. 2003;14(5):1200-11.

49. Krendel M, Kim SV, Willinger T, Wang T, Kashgarian M, Flavell RA, et al. Disruption of Myosin 1e promotes podocyte injury. J Am Soc Nephrol. 2009;20(1):86-94. https://doi.org/10.1681/ ASN.2007111172.

50. Mele C, Iatropoulos $\mathrm{P}$, Donadelli R, Calabria A, Maranta R, Cassis $\mathrm{P}$, et al. MYO1E mutations and childhood familial focal segmental glomerulosclerosis. N Engl J Med. 2011;365(4):295-306. https://doi.org/10.1056/NEJMoa1101273.

51. Plageman TF Jr, Chauhan BK, Yang C, Jaudon F, Shang X, Zheng Y, et al. A Trio-RhoA-Shroom3 pathway is required for apical constriction and epithelial invagination. Development. 2011;138(23):5177-88. https://doi.org/10.1242/dev.067868.

52. Khalili H, Sull A, Sarin S, Boivin FJ, Halabi R, Svajger B, et al. Developmental origins for kidney disease due to shroom3 deficiency. J Am Soc Nephrol. 2016;27(10):2965-73. https://doi. org/10.1681/asn.2015060621.

53. Mukerji N, Damodaran TV, Winn MP. TRPC6 and FSGS: the latest TRP channelopathy. Biochim Biophys Acta. 2007;1772(8):859-68. https://doi.org/10.1016/j.bbadi s.2007.03.005.

54. Krall P, Canales CP, Kairath P, Carmona-Mora P, Molina J, Carpio JD, et al. Podocyte-specific overexpression of wild type or mutant trpc6 in mice is sufficient to cause glomerular disease. PLoS One. 2010;5(9):e12859. https://doi.org/10.1371/journ al.pone.0012859.

55. Hoffmann S, Podlich D, Hahnel B, Kriz W, Gretz N. Angiotensin II type 1 receptor overexpression in podocytes induces glomerulosclerosis in transgenic rats. J Am Soc Nephrol. 2004;15(6):1475-87.

56. Lee DY, Kim W, Kang SK, Koh GY, Park SK. Angiotensin-converting enzyme gene polymorphism in patients with minimalchange nephrotic syndrome and focal segmental glomerulosclerosis. Nephron. 1997;77(4):471-3.

57. Zhou TB, Qin YH, Su LN, Lei FY, Huang WF, Zhao YJ, et al. The association between angiotensin-converting enzyme insertion/deletion gene variant and risk of focal segmental glomerulosclerosis: a systematic review and meta-analysis. J Renin Angiotensin Aldosterone Syst. 2011;12(4):624-33. https://doi. org/10.1177/1470320311410584.

58. Roselli S, Heidet L, Sich M, Henger A, Kretzler M, Gubler MC, et al. Early glomerular filtration defect and severe renal disease in podocin-deficient mice. Mol Cell Biol. 2004;24(2):550-60.

59. Mollet G, Ratelade J, Boyer O, Muda AO, Morisset L, Lavin TA, et al. Podocin inactivation in mature kidneys causes focal segmental glomerulosclerosis and nephrotic syndrome. J Am Soc Nephrol. 2009;20(10):2181-9. https://doi.org/10.1681/ASN.20090 40379.

60. Kestila M, Lenkkeri U, Mannikko M, Lamerdin J, McCready P, Putaala $\mathrm{H}$, et al. Positionally cloned gene for a novel glomerular protein-nephrin-is mutated in congenital nephrotic syndrome. Mol Cell. 1998;1(4):575-82.

61. Putaala H, Soininen R, Kilpelainen P, Wartiovaara J, Tryggvason $\mathrm{K}$. The murine nephrin gene is specifically expressed in kidney, brain and pancreas: inactivation of the gene leads to massive proteinuria and neonatal death. Hum Mol Genet. 2001;10(1):1-8.

62. Rantanen M, Palmen T, Patari A, Ahola H, Lehtonen S, Astrom E, et al. Nephrin TRAP mice lack slit diaphragms and show 
fibrotic glomeruli and cystic tubular lesions. J Am Soc Nephrol. 2002;13(6):1586-94.

63. Juhila J, Lassila M, Roozendaal R, Lehtonen E, Messing M, Langer B, et al. Inducible nephrin transgene expression in podocytes rescues nephrin-deficient mice from perinatal death. Am J Pathol. 2010;176(1):51-63. https://doi.org/10.2353/ajpat h.2010.080843.

64. Tsvetkov D, Hohmann M, Anistan YM, Mannaa M, Harteneck C, Rudolph B, et al. A CD2AP mutation associated with focal segmental glomerulosclerosis in young adulthood. Clin Med Insights Case Rep. 2016;9:15-9. https://doi.org/10.4137/CCRep.S30867.

65. Shih NY, Li J, Karpitskii V, Nguyen A, Dustin ML, Kanagawa $\mathrm{O}$, et al. Congenital nephrotic syndrome in mice lacking CD2associated protein. Science. 1999;286(5438):312-5.

66. Shih NY, Li J, Cotran R, Mundel P, Miner JH, Shaw AS. CD2AP localizes to the slit diaphragm and binds to nephrin via a novel C-terminal domain. Am J Pathol. 2001;159(6):2303-8. https:// doi.org/10.1016/S0002-9440(10)63080-5.

67. Huber TB, Kwoh C, Wu H, Asanuma K, Godel M, Hartleben B, et al. Bigenic mouse models of focal segmental glomerulosclerosis involving pairwise interaction of CD2AP, Fyn, and synaptopodin. J Clin Invest. 2006;116(5):1337-45. https://doi.org/10.1172/ JCI27400.

68. Hartleben B, Widmeier E, Suhm M, Worthmann K, Schell C, Helmstadter M, et al. aPKClambda/iota and aPKCzeta contribute to podocyte differentiation and glomerular maturation. J Am Soc Nephrol. 2013;24(2):253-67. https://doi.org/10.1681/ASN.20120 60582.

69. Huber TB, Hartleben B, Winkelmann K, Schneider L, Becker JU, Leitges M, et al. Loss of podocyte aPKClambda/iota causes polarity defects and nephrotic syndrome. J Am Soc Nephrol. 2009;20(4):798-806. https://doi.org/10.1681/ASN.2008080871.

70. Hirose T, Satoh D, Kurihara H, Kusaka C, Hirose H, Akimoto $\mathrm{K}$, et al. An essential role of the universal polarity protein, aPKClambda, on the maintenance of podocyte slit diaphragms. PLoS One. 2009;4(1):e4194. https://doi.org/10.1371/journ al.pone.0004194.

71. Satoh D, Hirose T, Harita Y, Daimon C, Harada T, Kurihara H, et al. aPKClambda maintains the integrity of the glomerular slit diaphragm through trafficking of nephrin to the cell surface. J Biochem. 2014;156(2):115-28. https://doi.org/10.1093/jb/mvu02 2.

72. Rocque BL, Babayeva S, Li J, Leung V, Nezvitsky L, Cybulsky $\mathrm{AV}$, et al. Deficiency of the planar cell polarity protein Vangl2 in podocytes affects glomerular morphogenesis and increases susceptibility to injury. J Am Soc Nephrol. 2015;26(3):576-86. https ://doi.org/10.1681/ASN.2014040340.

73. Babayeva S, Zilber Y, Torban E. Planar cell polarity pathway regulates actin rearrangement, cell shape, motility, and nephrin distribution in podocytes. Am J Physiol Renal Physiol. 2011;300(2):F549-60. https://doi.org/10.1152/ajprenal.00566 2009 .

74. Gebeshuber CA, Kornauth C, Dong L, Sierig R, Seibler J, Reiss M, et al. Focal segmental glomerulosclerosis is induced by microRNA-193a and its downregulation of WT1. Nat Med. 2013;19(4):481-7. https://doi.org/10.1038/nm.3142.

75. Kietzmann L, Guhr SS, Meyer TN, Ni L, Sachs M, Panzer U, et al. MicroRNA-193a regulates the transdifferentiation of human parietal epithelial cells toward a podocyte phenotype. J Am Soc Nephrol. 2015;26(6):1389-401. https://doi.org/10.1681/ASN.20140 20190.

76. Wang Y, Jarad G, Tripathi P, Pan M, Cunningham J, Martin DR, et al. Activation of NFAT signaling in podocytes causes glomerulosclerosis. J Am Soc Nephrol. 2010;21(10):1657-66. https://doi. org/10.1681/ASN.2009121253.
77. Schlondorff J, Del Camino D, Carrasquillo R, Lacey V, Pollak MR. TRPC6 mutations associated with focal segmental glomerulosclerosis cause constitutive activation of NFAT-dependent transcription. Am J Physiol Cell Physiol. 2009;296(3):C558-69. https ://doi.org/10.1152/ajpcell.00077.2008.

78. Maezawa Y, Onay T, Scott RP, Keir LS, Dimke H, Li C, et al. Loss of the podocyte-expressed transcription factor Tcf21/Pod1 results in podocyte differentiation defects and FSGS. J Am Soc Nephrol. 2014;25(11):2459-70. https://doi.org/10.1681/ASN.2013121307.

79. Hall G, Gbadegesin RA, Lavin P, Wu G, Liu Y, Oh EC, et al. A novel missense mutation of Wilms' Tumor 1 causes autosomal dominant FSGS. J Am Soc Nephrol. 2015;26(4):831-43. https:// doi.org/10.1681/asn.2013101053.

80. Lal MA, Andersson AC, Katayama K, Xiao Z, Nukui M, Hultenby $\mathrm{K}$, et al. Rhophilin-1 is a key regulator of the podocyte cytoskeleton and is essential for glomerular filtration. J Am Soc Nephrol. 2015;26(3):647-62. https://doi.org/10.1681/ASN.2013111195.

81. Zenker M, Aigner T, Wendler O, Tralau T, Muntefering H, Fenski R, et al. Human laminin beta2 deficiency causes congenital nephrosis with mesangial sclerosis and distinct eye abnormalities. Hum Mol Genet. 2004;13(21):2625-32. https://doi.org/10.1093/ hmg/ddh284.

82. Aydin B, Ipek MS, Ozaltin F, Zenciroglu A, Dilli D, Beken S, et al. A novel mutation of laminin beta-2 gene in Pierson syndrome manifested with nephrotic syndrome in the early neonatal period. Genetic counseling, Geneva. 2013;24(2):141-7.

83. Zemrani B, Cachat F, Bonny O, Giannoni E, Durig J, Fellmann $\mathrm{F}$, et al. A novel LAMB2 gene mutation associated with a severe phenotype in a neonate with Pierson syndrome. European journal of medical research. 2016;21:19. https://doi.org/10.1186/s4000 $1-016-0215-z$

84. Suh JH, Jarad G, VanDeVoorde RG, Miner JH. Forced expression of laminin $\beta 1$ in podocytes prevents nephrotic syndrome in mice lacking laminin $\beta 2$, a model for Pierson syndrome. Proc Natl Acad Sci USA. 2011;108(37):15348-53. https://doi.org/10.1073/ pnas. 1108269108.

85. D'Agati VD, Fogo AB, Bruijn JA, Jennette JC. Pathologic classification of focal segmental glomerulosclerosis: a working proposal. Am J Kidney Dis. 2004;43(2):368-82.

86. Lim BJ, Yang JW, Do WS, Fogo AB. Pathogenesis of Focal Segmental Glomerulosclerosis. J Pathol Translat Med. 2016;50(6):405-10. https://doi.org/10.4132/jptm.2016.09.21.

87. Suzuki T, Matsusaka T, Nakayama M, Asano T, Watanabe T, Ichikawa I, et al. Genetic podocyte lineage reveals progressive podocytopenia with parietal cell hyperplasia in a murine model of cellular/collapsing focal segmental glomerulosclerosis. Am J Pathol. 2009;174(5):1675-82. https://doi.org/10.2353/ajpat h. 2009.080789 .

88. D'Agati VD. The spectrum of focal segmental glomerulosclerosis: new insights. Curr Opin Nephrol Hypertens. 2008;17(3):271-81. https://doi.org/10.1097/MNH.0b013e3282f94a96.

89. Sellier-Leclerc AL, Duval A, Riveron S, Macher MA, Deschenes $\mathrm{G}$, Loirat $\mathrm{C}$, et al. A humanized mouse model of idiopathic nephrotic syndrome suggests a pathogenic role for immature cells. J Am Soc Nephrol. 2007;18(10):2732-9. https://doi.org/10.1681/ asn.2006121346.

90. Saleem MA, Kobayashi Y. Cell biology and genetics of minimal change disease. F1000Research. 2016;5. https://doi.org/10.12688 /f1000research.7300.1.

91. Bierzynska A, Soderquest K, Koziell A. Genes and podocytesnew insights into mechanisms of podocytopathy. Front Endocrinol. 2014;5:226. https://doi.org/10.3389/fendo.2014.00226. 